\title{
REVISED Automatic migraine classification using artificial neural
}

\section{networks [version 2; peer review: 1 approved, 2 approved with}

\section{reservations]}

\section{Paola A. Sanchez-Sanchez (D) José Rafael García-González, Juan Manuel Rúa Ascar}

School of Engineering, Universidad Simón Bolívar, Barranquilla, Atlántico, 00000, Colombia

V2 First published: 16 Jun 2020, 9:618

https://doi.org/10.12688/f1000research.23181.1

Latest published: 17 Jul 2020, 9:618

https://doi.org/10.12688/f1000research.23181.2

\section{Abstract}

Background: Previous studies of migraine classification have focused on the analysis of brain waves, leading to the development of complex tests that are not accessible to the majority of the population. In the early stages of this pathology, patients tend to go to the emergency services or outpatient department, where timely identification largely depends on the expertise of the physician and continuous monitoring of the patient. However, owing to the lack of time to make a proper diagnosis or the inexperience of the physician, migraines are often misdiagnosed either because they are wrongly classified or because the disease severity is underestimated or disparaged. Both cases can lead to inappropriate, unnecessary, or imprecise therapies, which can result in damage to patients' health.

Methods: This study focuses on designing and testing an early classification system capable of distinguishing between seven types of migraines based on the patient's symptoms. The methodology proposed comprises four steps: data collection based on symptoms and diagnosis by the treating physician, selection of the most relevant variables, use of artificial neural network models for automatic classification, and selection of the best model based on the accuracy and precision of the diagnosis.

Results: The artificial neural network models used provide an excellent classification performance, with accuracy and precision levels $>97 \%$ and which exceed the classifications made using other model, such as logistic regression, support vector machines, nearest neighbor, and decision trees.

Conclusions: The implementation of migraine classification through artificial neural networks is a powerful tool that reduces the time to obtain accurate, reliable, and timely clinical diagnoses.

Keywords

artificial neural networks, migraine, supervised learning, automatic classification techniques
Open Peer Review

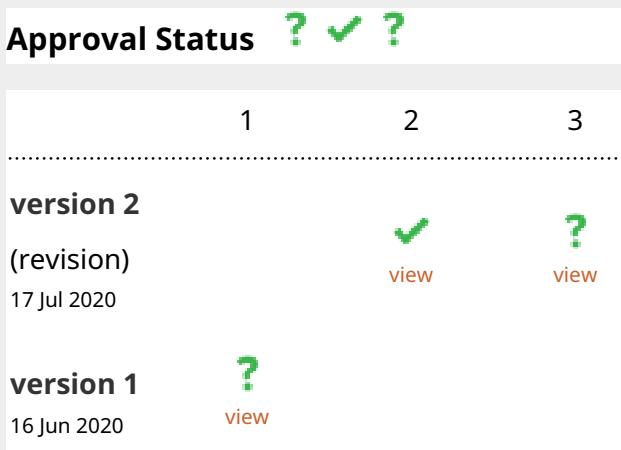

1. Shengyuan Yu, Medical School of Chinese PLA, Beijing, China

2. Hugo Ordoñez Eraso ID, University of San Buenaventura, Cali, Colombia

Universidad de Cauca, Popayán, Colombia

3. Stelmo Magalhães Barros Netto (iD,

Federal University of Maranhão, São Luís, Brazil

Any reports and responses or comments on the article can be found at the end of the article. 


\section{incf}

This article is included in the INCF gateway.

Corresponding author: Paola A. Sanchez-Sanchez (psanchez9@unisimonbolivar.edu.co)

Author roles: Sanchez-Sanchez PA: Conceptualization, Formal Analysis, Methodology, Software, Validation, Visualization, Writing Original Draft Preparation, Writing - Review \& Editing; García-González JR: Conceptualization, Methodology, Writing - Review \& Editing; Rúa Ascar JM: Conceptualization, Data Curation, Investigation, Writing - Original Draft Preparation

Competing interests: No competing interests were disclosed.

Grant information: The author(s) declared that no grants were involved in supporting this work.

Copyright: (c) 2020 Sanchez-Sanchez PA et al. This is an open access article distributed under the terms of the Creative Commons Attribution License, which permits unrestricted use, distribution, and reproduction in any medium, provided the original work is properly cited.

How to cite this article: Sanchez-Sanchez PA, García-González JR and Rúa Ascar JM. Automatic migraine classification using artificial neural networks [version 2; peer review: 1 approved, 2 approved with reservations] F1000Research 2020, 9:618

https://doi.org/10.12688/f1000research.23181.2

First published: 16 Jun 2020, 9:618 https://doi.org/10.12688/f1000research.23181.1 


\section{REVISED Amendments from Version 1}

1. We have rewritten the preface focusing the content on aspects relevant to research such as a short introduction to migraine, the current state of research in the area, the problems surrounding the classification of different types of migraine, how artificial neural networks help to solve the problems and why of this study.

2. The methods section was rewritten for better clarity in the writing. Clarifications were made regarding the inclusion and exclusion criteria, which have been described in the results.

3. The discussion section was expanded to include the validation of the results with the different models applied, the significance of the results obtained, an account of some aspects that justify the development of classification models with artificial neural networks and the comparison with some studies previous. Likewise, the conclusions were expanded to include future research fields.

Any further responses from the reviewers can be found at the end of the article

\section{Introduction}

Cephalalgia or headache represents one of the most common types of pain experienced by humans. Headaches usually occur intermittently. The most frequent forms correspond to migraine and tension headache. Migraines are classified as chronic disorders of the nervous system and are characterized by the onset of recurrent symptoms or episodes associated with headache, which can range from moderate to severe pain and includes throbbing or vibrating pain; furthermore, migraines can be experienced unilaterally or bilaterally and can trigger other symptoms, such as nausea, vomiting, weakness, and light and sound sensitivity (Charles, 2013; Deza, 2010; IHS, 2018).

Both chronic and recurrent/relapsing headaches can cause pain and distress, but they rarely reflect a serious health problem. However, any change in the pattern or nature of the headache could be a sign of a serious complication, i.e., change in pain frequency from sporadic to frequent or pain severity from mild to acute; hence, medical attention should be sought as soon as possible (Goadsby et al., 2002).

Although headache is generally a benign and transitory disorder that in most cases ceases spontaneously or with the aid of analgesics, it can also be caused by a serious life-threatening illness such as meningitis, brain tumor, hypercholesterolemia, heart problems, or subarachnoid hemorrhage (arteriovenous malformation). On the other hand, certain types of headaches, such as migraines, although benign, cause much suffering in affected individuals and represent an economic burden because of the high number of work-loss hours they cause (Trillos, 2010).

In 1988, the Classification Committee of the International Headache Society (IHS, 2018) published the current classification of headache types, which divides headaches into primary and secondary headaches. Primary headaches include migraines, tension-type headaches, paroxysmal headaches (cluster headaches and paroxysmal hemicrania), and benign miscellaneous headaches. Secondary headaches are those caused by vascular disease, infection, tumors, alteration in cerebrospinal fluid production, cranial trauma, neuralgia, etc.

Discrimination among migraines with and without aura and other types of migraines and headaches is established based on the specific criteria established by the International Headache Society (Charles, 2018; IHS, 2018; Rasmussen \& Olesen, 1992; Viana et al., 2017). To diagnose migraines, the patient's medical history and symptoms are assessed and a physical and neurological examination is performed; these are sometimes accompanied by specialized examinations such as magnetic resonance imaging, tomography, electroencephalogram, and lumbar puncture (Evans, 2019). An important part of diagnosing migraines is discarding other medical conditions that could be causing the symptoms (Altintop et al., 2017; Diamond et al., 2007; Giffin et al., 2003; Goadsby \& Holland, 2019; Karsan \& Goadsby, 2018; Maniyar et al., 2015).

Isaza et al. (1997) conducted a statistical study in mid-1981 and 1989 in Colombia and showed that $11.6 \%$ of women and $3.4 \%$ of men suffered from migraines. Similarly, Ramírez \& Urrea (2012) reported that in 1997, of 3,401 patients assessed in Colombia in the outpatient department of the neurology service, $848(24.93 \%)$ were due to primary headache, which is an important reason for outpatient consultation. Migraines occurred in $617(18.14 \%)$ patients, with aura in $255(7.5 \%)$ and no aura in $362(10.64 \%)$.

Previous studies on migraine classification focused on the neurological or genetic aspects of the disease, leading to investigations that allowed for the classification of various types of migraines based on the study of encephalograms (Akben et al., 2012; Akben et al., 2010; Akben et al., 2016; Alkan \& Akben, 2011; Altintop et al., 2017; Bellottia et al., 2007; Martins-Oliveira et al., 2017; Subasi et al., 2018), signals emitted by body temperature sensors, blood oxygen, heart rate, and electrodermal activity data (Chong et al., 2017; Koskimäki et al., 2017; Schwedt, 2013), or genetic analysis (Gormley et al., 2016). Although these studies attempted to classify migraines with precision levels of $>70 \%$, the methods used required a direct measurement of the variables using medical devices connected to the patient, which can cause variation in the data; lead to long waiting times for the appointment of specialized examinations, particularly in Latin American countries; or result in a lack of availability of medical equipment in rural regions. As stated previously (Alkan \& Akben, 2011), numerous investigations have attempted to develop automatic diagnostic methods for migraines. However, no definitive diagnostic method for migraines has yet been accepted by the authorities on the subject (IHS).

Currently, there is a recurrent problem in the diagnosis and treatment of migraines, which includes, among others, the following needs: (i) proper reading and identification of the patient's primary and secondary symptoms, (ii) precise and timely identification of the type of migraine, (iii) continuous monitoring of the symptoms, and (iv) adequate treatment. In the early stages of the pathology, patients visit the emergency services or 
outpatient consultation departments, where timely identification largely depends on the expertise of the treating physician and the continuous monitoring of the patient (Burch et al., 2018; Burch, 2019; Deza, 2010; Evans \& Johnston, 2011; Trillos, 2010; Wang et al., 2019). However, owing to the scarcity of time to establish a diagnosis, the inexperience of the physician, or shortcomings in the patient-physician communication of symptoms, the pathology is often misdiagnosed or the severity of the disease is underestimated, leading to inappropriate, unnecessary, or imprecise therapies, which can result in complex damages to patients' health (Evans \& Johnston, 2011). Migraines can be misdiagnosed as tension headache, sinus headache, or other types of headache. A diagnosis of migraine should be considered when there are recurrent and debiliting headaches without secondary warning signs (Burch et al., 2018; Burch, 2019; Wang et al., 2019). Therefore, misdiagnosis or incorrect classification of the type of migraine and inadequate treatment of the pathology constitute the underlying problem associated with migraines (Deza, 2010; Trillos, 2010).

The need for tools aimed at enabling appropriate decision-making has led to an accelerated interest in the development of data classification models in recent decades, which is especially intended to overcome the theoretical, conceptual, and practical limitations of many of the techniques currently available. This has resulted in the emergence of a wide range of models, among which artificial neural networks have demonstrated high potential given their adaptability, generalizability, and learning capabilities and because of the possibility of representing nonlinear relationships (Sánchez-Sánchez \& GarcíaGonzález, 2017). Artificial neural networks and their recent architectures, such as deep neural networks, have been used effectively in data classification tasks and display better results than other techniques, such as logistic regression, decision trees, Bayesian classifiers, etc.; their strength lies in their high capacity to dynamically create complex prediction functions and emulate human learning (Nikam, 2015; Sánchez-Sánchez \& García-González, 2017; Sánchez-Sánchez \& García-González, 2018).

This article seeks to contribute to the early identification of different types of migraines through the use of supervised learning techniques based on artificial intelligence, which allow overcoming the difficulties encountered. The purpose of this study is to develop a classification model that allows the determination of the type of migraine a patient suffers based on the analysis of its symptoms and medical history. The novelty, significance, and relevance of this study are outlined as follows:

- An indirect method aimed at classifying the type of migraine experienced by a patient, which, unlike existing methodologies, does not use procedures requiring brain wave measurement or the use of sensors.

- The systematic migraine classification process used includes the stages of data collection based on symptoms and diagnosis by the treating physician, selection of the most relevant features, use of different classification models, and selection of the most suitable model based on the accuracy and precision of diagnosis.

\section{Methods}

The strategy developed here is based on a systemic approach oriented to the specification of artificial neural network models for the classification of migraines with and without aura, highlighting the relevance of considering key aspects that lead to strong implications in their application, such as the selection of variables and the performance measures that allow for the selection of the best model.

Starting from the existence of a data source that includes various typical symptoms of patients with migraines, Figure 1 outlines the steps in the classification of patients with migraines and the comparison model (García-González et al., 2019; Sánchez-Sánchez et al., 2019b).

Note: It is important to understand that the proposed methodology does not include the data collection process. In the current research, a retrospective database is used, to which the proposed methodology is applied. The results section describes the data population and the selection and exclusion criteria.

The elements included in Figure 1 are discussed below.

1. Selection: The data selection phase is directed toward the preliminary analysis of the various data sources (if any), their features, and aspects related to the environment in which they are obtained. This selection can be defined as a process of approximation to the available information through subjective analysis and statistical treatment in order to infer the hidden structure of data.

Knowing the goals and the data that will enable this process are key factors for a successful selection process.

2. Processing: Data processing consists of analyzing and transforming the input variables with the aim of minimizing noise, highlighting important relationships, and detecting errors to enable the recognition of hidden patterns. Processing comprises four types of processes: the first aimed at minimizing noise via the transformation of the object data and the elimination of irregular patterns (atypical data; poor typing; blank, incomplete, and inconsistent data, etc.); the second aimed at scaling the large-sized object data; the third aimed at considering the syntactic transformations of the object data and facilitating its handling, without leading to changes in the results; and the fourth aimed at the selection of the variables, characteristics, or attributes that will be taken into account. This selection largely depends on the knowledge that the data modeler has on the data sources, and it is his/her task to decide whether to include each variable in the model following some previously established criteria. Typically, not all potential variables are equally informative as they may be correlated, present noise, or have no meaningful relationship with the classification (Londoño González \& Sánchez, 2015) 




Figure 1. Flow diagram for the classification of patients with migraine.

3. Classification: Classification involves searching patterns of interest that express dependency on the data and allows groups with similar features to be established. The process essentially consists of assigning each individual (entity or data) its own category or class, thereby creating sets of individuals sharing some feature that differentiate them from the rest. Classes can be binary, Yes or No, or multiclass, which include more than two categories. At this stage, machine learning, whose objective is to develop techniques that allow computers to learn, is used.

The past few years have seen the proliferation of different automatic classification techniques based in learning machine, including artificial neural networks, decision trees, logistic regression, Bayesian classifiers, nearest neighbor, support vector machines (SVMs), and multiple discriminant analysis (Doupe et al., 2019; Waring et al., 2020).

In this article, because of the robustness of the data management technique, adaptability, and acknowledged generalization capacity, artificial neural networks are used to classify patients with migraines. Artificial neural network is represented as a three-layer model: an input layer, one or more hidden layers, and an output layer (Figure 2) (Sánchez-Sánchez et al., 2020b). An input layer represents the variables that influence the model, hidden layers perform the processing, and the output layer corresponds to the various migraine classes.

Logistic regression models, SVMs, nearest neighbor, and decision trees are also implemented in order to compare data collected using other classification techniques.

4. Interpretation: In this phase, evaluation of the quality of the model is performed by analyzing and comparing the results from different metrics used for the classification based on the data obtained in the classification stage, which is aimed at understanding the main characteristics of the model.
For classification problems, common performance metrics are as follows:

- Accuracy: Proportion of correctly classified instances.

- Precision: Also called positive predictive value, it represents the fraction of correctly predicted positives among those classified as positive.

\section{Results}

Method: We used the proposed methodology for the classification of migraines.

Population: This study used a database comprising 400 retrospective medical records of users diagnosed with various pathologies associated with migraines. Data was compiled in the research of the master's thesis "Analysis of Artificial Neural Network Models, for a Migraine Diagnosis System with Aura and without Aura" (De la Hoz et al., 2014). Data were recorded by trained medical personnel at the Hospital Materno Infantil de Soledad during the first quarter of 2013. The compiled database contains information regarding patient identification, healthcare provider identification, treating physician identification, symptoms, diagnosis, and treatment. However, this study only uses symptoms and diagnosis. No patient identifiable data was required. See underlying data (Sanchez-Sanchez et al., 2020a).

As inclusion criteria, we have adult users diagnosed with migraine-associated pathologies. Users with other pathologies are excluded.

Procedure: Selection and processing: Based on compiled database, tasks related to noise elimination, error detection, and data translation into numerical variables were performed.

Variables that influence the identification of the type of migraine were selected, focusing on symptoms and diagnosis and 


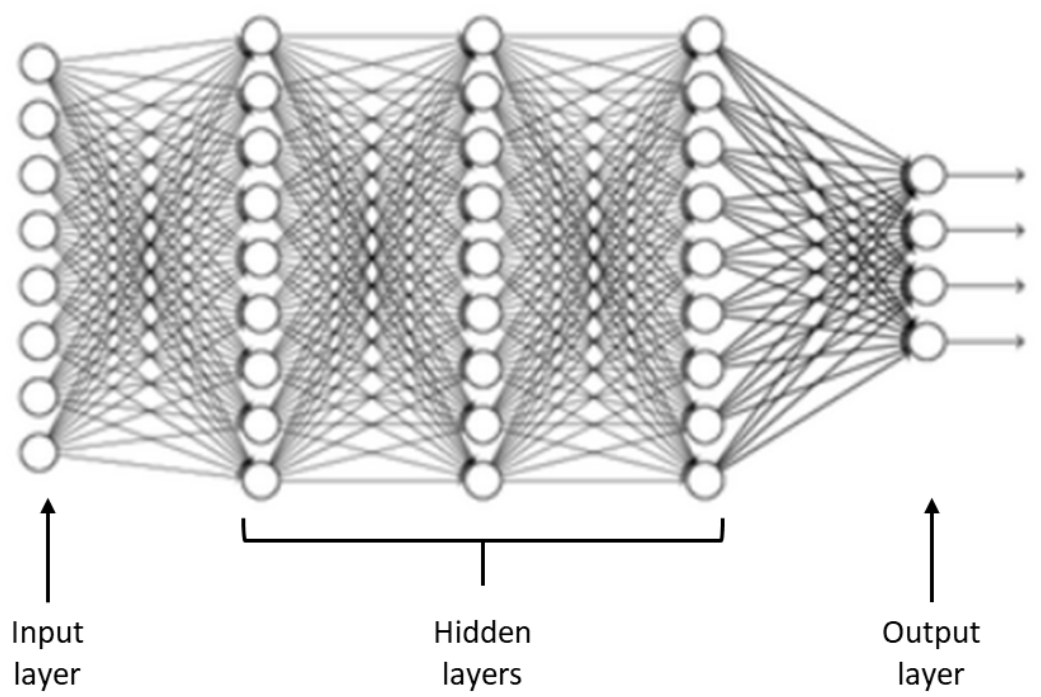

Figure 2. General scheme of an artificial neural network.

disregarding identification and treatment variables. This led to a selection of 23 variables associated with the symptoms or signs that a patient may present, and 1 variable associated with the diagnosis that allows the identification of the type of migraine. Table 1 presents a list of the 24 identified variables and their description.

The type of variable states the different values that it can assume and can be either continuous, e.g., age, or binary, e.g., nausea. The variable "Type" indicates the diagnosis issued by the treating physician based on the symptoms and medical record of the patient, with the possibility of presenting of one of the following classifications:

1. Typical aura with migraine

2. Migraine without aura

3. Typical aura without migraine

4. Familial hemiplegic migraine

5. Sporadic hemiplegic migraine

6. Basilar-type aura

\section{Other}

Figure 3 presents the distribution of cases according to the classification of migraine types carried out in the study and which serves as a criterion for verifying accuracy and precision.

Tests are conducted with the complete dataset (23 variables), and variable reduction, recursive elimination of variables, and selection of the best number through cross-validation is applied, the latter in order to eliminate variables with redundant information. This produces a reduced set of 18 variables.
Classification: Preprocessed data are used as inputs to five different classification models: a multilayer perceptron-type artificial neural network (MLP), which is validated using different network configurations that differ in the number of neurons and hidden layers; a logistic regression model; an SVM model; a nearest neighbor model; and an optimized classification and regression tree (CART).

Python 3 script is used with Scikit-learn 0.23.1 ${ }^{1}$ and pandas' 1.0.4 libraries (Sanchez-Sanchez et al., 2020a).

The artificial neural network model used is equivalent to an MLP trained using backpropagation. The configuration parameters used for the artificial neural network models are as follows:

- Input neurons: 23 variables corresponding to the first 23 variables presented in Table 1 for the complete model and 18 variables for the reduced model.

- Hidden neurons: An iterative optimization process is performed on each hidden layer, varying from 1 to 25 . The number of neurons per layer is based on the best accuracy obtained.

- Hidden layers: An incremental construction process of 1 to 4 layers is conducted. The best number of neurons from the previous hidden layer is taken and is iteratively increased from 1 to 25 in the new hidden layer.

- Output neurons: Seven neurons that correspond to each class of migraine

- Transfer function: Logistics

${ }^{1}$ Scikit-learn (formerly scikits.learn and also known as sklearn) is a free software machine learning library for the Python programming language. https://scikit-learn.org 


\section{Table 1. List of identified variables.}

\begin{tabular}{|c|c|c|c|c|c|}
\hline & Description & Name & & Description & Name \\
\hline 1 & Patient's age & Age & 13 & Lack of speech coordination & Dysphasia \\
\hline 2 & duration of last episode in days & Duration & 14 & Disarticulated sounds and words & Dysarthria \\
\hline 3 & $\begin{array}{l}\text { Frequency of episodes per } \\
\text { month }\end{array}$ & Frequency & 15 & Dizziness & Vertigo \\
\hline 4 & $\begin{array}{l}\text { Unilateral or bilateral pain } \\
\text { location }\end{array}$ & Location & 16 & Ringing in the ears & Tinnitus \\
\hline 5 & Throbbing or constant pain & Character & 17 & Hearing loss & Hypoacusis \\
\hline 6 & $\begin{array}{l}\text { Pain intensity, i.e., mild, } \\
\text { medium, or severe }\end{array}$ & Intensity & 18 & Double vision & Diplopia \\
\hline 7 & Nauseous feeling & Nausea & 19 & $\begin{array}{l}\text { Simultaneous frontal eye field and } \\
\text { nasal field defect and in both eyes }\end{array}$ & Visual defect \\
\hline 8 & Vomiting & Vomit & 20 & Lack of muscle control & Ataxia \\
\hline 9 & Noise sensitivity & Phonophobia & 21 & Jeopardized conscience & Conscience \\
\hline 10 & Light sensitivity & Photophobia & 22 & Simultaneous bilateral paresthesia & Paresthesia \\
\hline 11 & Reversible visual symptoms & Visual & 23 & Family background & Family \\
\hline 12 & Reversible sensory symptoms & Sensory & 24 & Diagnosis of migraine type & Type \\
\hline
\end{tabular}

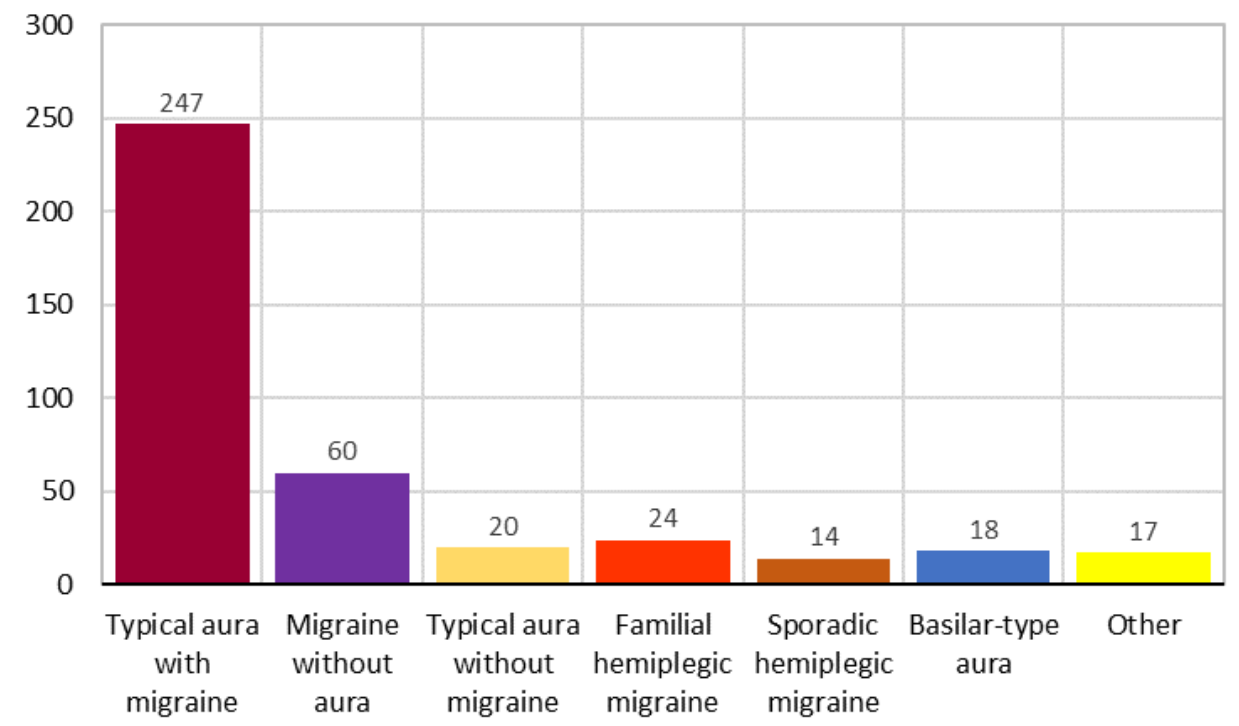

Figure 3. Number of cases by type of migraine.

- Performance metrics: Accuracy and precision

- Learning algorithm: Adam ${ }^{2}$

- Number of epochs: 2000

Logistic regression uses regularization with built-in cross-validation, which automatically selects the best hyperparameters for model fit. A 10-fold and random restart model was used ${ }^{3}$.

${ }^{2}$ arXiv: 1412.6980

${ }^{3}$ https://scikit-learn.org/stable/modules/linear_model.html\#logistic-regression
The SVM model uses the SVC function for classification, in which the fit time quadratically scales with the number of samples ${ }^{4}$.

In the nearest neighbor model, the optimal number of neighbors is estimated based on the accuracy, and the Euclidean function with uniform weights is used as a distance measure.

${ }^{4}$ https://scikit-learn.org/stable/modules/generated/sklearn.svm.SVC. html\#sklearn.svm.SVC 
The decision tree model included in the Scikit-learn library corresponds to an optimized version of CART (Classification and Regression Trees) that uses discrete numerical variables and where an iterative process is used to fit the number of levels based on accuracy.

In all cases, the dataset is divided into two sets: training and testing, the first corresponding to $80 \%$ of the data (320) and the second to $20 \%$ (80).

\section{Discussion}

Results were validated based on the type of migraine diagnosed by the treating physician and using the respective measurement made during the classification process provided by the artificial neural network.

Table 2 presents the results of the performance measures for various artificial neural network configurations and classification models. Precision, a metric calculated independently for each of the classes, is taken as the weighted average of the seven migraine classes.

The results presented in Table 2 indicate the following results:

- The maximum accuracy for both 23 and 18 variables is obtained by using a artificial neural network model with 10 hidden neurons, which results in an accuracy of 97.5\%. This means that the classification of migraines by the artificial neural network coincides with that issued by the treating physician in $97 \%$ of the 80 cases comprising the test set.

- The artificial neural network models show accuracies and precisions $>90 \%$, highlighting values obtained with the artificial neural network model with 10 hidden neurons and a hidden layer for 23 variables and 20 hidden neurons for 18 variables, which reaches values $>97 \%$ in both metrics, thereby indicating adequate classification.

- Those models with all variables have accuracies $>80 \%$, with the exception of the nearest neighbor model, which strongly demonstrates that the predicted values coincide with the real values, allowing for the correct classification of the different types of migraine in percentages $>80 \%$.

- The maximum average weighted precision was obtained with the artificial neural network model with a layer of 20 hidden neurons that was reduced to 18 variables, which obtained a value of $98 \%$; this indicates that there is a $98 \%$ probability that the model classifies the migraine within a certain type and that the treating physician has also classified it as such.

- The precisions obtained using logistic regression and SVM models do not differ greatly from the value obtained using artificial

\begin{tabular}{|c|c|c|c|}
\hline \multicolumn{4}{|c|}{ Complete model with 23 variables } \\
\hline Hidden Layers & $\begin{array}{l}\text { Internal configuration } \\
\text { (number of hidden neurons) }\end{array}$ & Accuracy & Precision \\
\hline 1 & 10 & 0.975 & 0.97 \\
\hline 2 & $(10,15)$ & 0.9625 & 0.97 \\
\hline 3 & $(10,15,15)$ & 0.9375 & 0.95 \\
\hline 4 & $(10,15,15,25)$ & 0.9375 & 0.94 \\
\hline \multicolumn{2}{|c|}{ Logistic regression } & 0,875 & 0.9563 \\
\hline \multicolumn{2}{|c|}{ Support vector machines } & 0.8625 & 0.9531 \\
\hline \multicolumn{2}{|l|}{ Nearest neighbor } & 0.7875 & 0.8719 \\
\hline \multicolumn{2}{|l|}{ Decision trees } & 0.8125 & 0.8100 \\
\hline \multicolumn{4}{|c|}{ Model reduced to 18 variables } \\
\hline Hidden Layers & $\begin{array}{l}\text { Internal configuration } \\
\text { (number of hidden neurons) }\end{array}$ & Accuracy & Precision \\
\hline 1 & 20 & 0.975 & 0.98 \\
\hline 2 & $(20,25)$ & 0.95 & 0.95 \\
\hline 3 & $(20,25,25)$ & 0.9375 & 0.92 \\
\hline 4 & $(20,25,25,20)$ & 0.85 & 0.79 \\
\hline \multicolumn{2}{|c|}{ Logistic regression } & 0,925 & 0.9467 \\
\hline \multicolumn{2}{|c|}{ Support vector machines } & 0.85 & 0.8844 \\
\hline \multicolumn{2}{|l|}{ Nearest neighbor } & 0,825 & 0.8594 \\
\hline \multicolumn{2}{|l|}{ Decision trees } & 0.8578 & 0.8650 \\
\hline
\end{tabular}


neural networks, even exceeding them in complex artificial neural network configurations with three and four hidden layers.

- Logistic regression, nearest neighbor, and decision tree models show better accuracy values when using models reduced to 18 variables.

- The values of accuracy and precision obtained using artificial neural network models do not favor the increase of hidden layers, leading to reduction phenomena in both metrics as the number of hidden layers and neurons increases, which is representative of overlearning processes.

The experiment results indicate that the performance of the proposed method yields satisfactory results and outperforms machine learning algorithms in migraine classification with a large gap in terms of accuracy and precision. The proposed method is generic as it does not need handcrafted features and can be easily adapted to different detection tasks, requiring minimal preprocessing. The strategy proposed has successfully transferred knowledge from the source to the target domain despite the limited dataset size. During the proposed approach, we observed that no over-fitting occurs to impact the classification accuracy adversely.

Some aspects that justify and favor the development of artificial neural network models for data classification are as follows (Sánchez-Sánchez et al., 2019a):

1. The data generating process is often unknown and difficult to identify, thereby limiting the capacity of parametric models to appropriately classify data. Artificial neural networks are self-adaptive models that do not require a priori assumptions about the problem under study, a highly desirable feature in cases in which the data generating mechanism is unknown (Qi \& Zhang, 2001).

2. Real data often show unstable behavior. The ability of the artificial neural network to learn and be generalized allows the model to learn complex behaviors directly from the data and correctly infer the unseen part of the data from the acquired knowledge (De Gooijer \& Kumar, 1992).

3. The relationships between the data and the variables that explain its behavior are complex. The universal approximation characteristics of artificial neural networks allow them to identify hidden dependencies, especially nonlinear dependencies (Cybenko, 1989; Franses \& Van Dijk, 2000; Hornik, 1991; Hornik et al., 1989), thereby favoring the representation of complex relationships.

4. Data units can be very large or very small. Artificial neural networks are flexible in relation with the values they receive and deliver and do not require prior treatment.

5. Data are obtained from multiple fields of knowledge. Their functional flexibility and characteristics as universal approximators allow artificial neural networks to represent complex behaviors regardless of the field of knowledge those data belong to.

\section{Comparison with previous studies}

For the sake of comparison, the performance of the classification obtained by the best model proposed here is compared with the results of the previously published work for classification of migraine in Table 3.

Table 3 presents the migraine classification results from previous studies using precision as a performance measure. The proposed artificial neural network model with 10 neurons (97\% precision with all variables and $98 \%$ precision with reduction to 18 variables) achieved a better performance compared to the methods in (Akben et al., 2012; Akben et al., 2016; De la Hoz \& Rúa et al., 2014; Jackowski et al., 2014; Krawczyk et al., 2013; Subasi et al., 2019; and Yin et al., 2015) with precisions $75.9 \%, 81 \%, 83.3 \%, 85 \%, 85.95 \%, 91.04 \%$ and $93.14 \%$, respectively..

\section{Conclusions}

This study presents the development of a methodology for migraine classification using artificial neural network models. The results show that artificial neural networks can achieve higher precision and accuracy than other classification models commonly used in machine learning, which is consistent with the results found when compared with various models proposed in the literature. The first experiments included 24 variables involved in migraine diagnosis, achieving a $97 \%$ precision level for the artificial neural network model. However, a second testing phase reduced the set of variables to 18 , reaching a precision of $98 \%$. This not only proves that the artificial neural network model is effective for the proper classification of the different types of migraine but shows that it can also be improved by considering a reduced set of variables that significantly affect the classification.

The implementation of migraine classification through artificial neural networks is a powerful tool whose potential has only incipiently been developed and which constitutes a valuable preliminary progress on the broad problem that automatic detection of migraines can encompass. The significance of this work lies in proposing an accurate and timely method of migraine classification that may support the diagnosis established by the treating physician based on an appropriate reading and identification of the primary and secondary symptoms that the patient presents and that results in the appropriate choice of treatment.

The main novelties are as follows:

- The development of a holistic methodology for migraine classification that encompasses selection of correct data and interpretation of the results obtained.

- The successful use of artificial neural network models for the classification of different types of migraines based on patients' 


\begin{tabular}{|c|c|c|}
\hline Reference study & $\begin{array}{l}\text { Classification } \\
\text { model }\end{array}$ & Precision \\
\hline $\begin{array}{l}\text { Migraine diagnosis support system based on } \\
\text { classifier ensemble (Jackowski et al., 2014) }\end{array}$ & LAD Tree & $75.9 \%$ \\
\hline $\begin{array}{l}\text { Automatic diagnosis of primary headaches by } \\
\text { machine learning methods (Krawczyk et al., 2013) }\end{array}$ & Random Forest & $81 \%$ \\
\hline $\begin{array}{l}\text { Analysis of repetitive flash stimulation frequencies } \\
\text { and record periods to detect migraine using } \\
\text { artificial neural network (Akben et al., 2012) }\end{array}$ & ANN & $83.3 \%$ \\
\hline $\begin{array}{l}\text { Classification of multi-channel EEG signals for } \\
\text { migraine detection (Akben et al., 2016) }\end{array}$ & SVM & $85 \%$ \\
\hline $\begin{array}{l}\text { Effect of photic stimulation for migraine detection } \\
\text { using random forest and discrete wavelet } \\
\text { transform (Subasi et al., 2019) }\end{array}$ & Random Forest & $85.95 \%$ \\
\hline $\begin{array}{l}\text { Analysis of Artificial Neural Networks Models, for a } \\
\text { System of Diagnoses of Migraines with Aura and } \\
\text { without Aura (De la Hoz \& Rúa et al., 2014) }\end{array}$ & ANN & $91.04 \%$ \\
\hline $\begin{array}{l}\text { A clinical decision support system for the } \\
\text { diagnosis of probable migraine and probable } \\
\text { tension-type headache based on case-based } \\
\text { reasoning (Yin et al., 2015) }\end{array}$ & CBR & $93.14 \%$ \\
\hline This study & ANN (complete) & $97 \%$ \\
\hline This study & ANN (reduced) & $98 \%$ \\
\hline
\end{tabular}

LAD - least absolute deviations, ANN - artificial neural network, SVM - support vector machine, CBR - case-based reasoning

symptoms, which use a database with data from patients who have experienced migraines and have been diagnosed by their treating physicians, resulting in a model that allows for the near-perfect distinction among the different types of migraine.

In addition, increasing the number of patient records in the database can lead to more accurate results in migraine classification because it enhances learning. Future research may be oriented to the comparison of different deep neural network architectures and the analysis of the treating physician's diagnosis versus the theoretical classification of the types of migraine.

\section{Data availability}

Underlying data

Code Ocean: Migraine Classification Model. https://doi. org/10.24433/CO.2826453.v1 (Sanchez-Sanchez et al., 2020a)

This project contains the following underlying data:

- $\quad$ Migraine.cvs (Dataset contain medical records of patient with migraines)

- $\quad$ Migraine Dataset Description.txt (Description of data.)
Reporting guidelines

Zenodo: STARD checklist for 'Automatic Migraine Classification Using Artificial Neural Networks' http://doi.org/10.5281/zenodo.3872279 (Sanchez-Sanchez, 2020)

Data are available under the terms of the Creative Commons Attribution 4.0 International license (CC-BY 4.0).

Software availability

Code for the model is available from Code Ocean: https://doi. org/10.24433/CO.2826453.v1 (code.ipynb)

License: GNU General Public License (GPL)

\section{Ethical considerations}

\section{Ethical approvals}

Data used in the recent study are the result of the master's thesis work of the author Juan Manuel Rúa Áscar, who had authorization for their academic use by the Hospital Materno Infantil de Soledad, in accordance with Colombian Law 1581 of 2012 and Decree 1377 of 2013 art. 10, which regulates the treatment of personal information and allows the use for scientific purposes, and that authorization is it extends for the current study. 
Ethics approval for the use of the original data in the current study was obtained from Universidad Simón Bolívar Research Ethics Committee on 12 May 2020 (reference PRO-CEI-USB-CE0328-00)

\section{Consent}

This research is not a clinical trial and doesn't involve any direct patient contact. Anonymized retrospective data collected as part of routine clinical care are included. As a retrospective patient records study, consent was not requested from individual patients. In such cases the ICO code of practice states that explicit consent is not generally required.

\section{Acknowledgments}

The authors express a posthumous recognition to Dr. Manuel Sánchez Rojas for his help in completing this article and his permanent availability to answer our questions and requirements.
Alkan A, Akben SB: Use of K-means clustering in migraine detection by using EEG records under flash stimulation. Int J Phys Sci. 2011; 6(4): 641-650. Reference Source

Akben SB, Subasi A, Tuncel D: Analysis of repetitive flash stimulation frequencies and record periods to detect migraine using artificial neural network. J Med Syst. 2012; 36(2): 925-931.

PubMed Abstract | Publisher Full Tex

Akben SB, Subasi A, Kiymik MK: Comparison of artificial neural network and support vector machine classification methods in diagnosis of migraine by using EEG. IEEE 18th Signal Processing and Communications Applications Conference, Diyarbakir, Turkey. 2010; 637-640.

Publisher Full Text

Akben SB, Tuncel D, Alkan A: Classification of multi-channel EEG signals for migraine detection. Biomed Res. 2016; 27(3): 743-748.

Reference Source

Altintop ÇG, Latifoğlu F, Yalabik A, et al:: Detection of differences between migraine and tension-type headache from electroencephalogram signals. 10th International Conference on Electrical and Electronics Engineering (ELECO), Bursa, Turkey. 2017; 524-528.

Reference Source

Bellottia R, De Carlo F, de Tommaso M, et al:: Classification of spontaneous EEG signals in migraine. Physica A Stat Mech Appl. 2007; 382(2): 549-556.

Publisher Full Text

Burch R: Migraine and tension-type headache: Diagnosis and treatment. Med Clin North Am. 2019; 103(2): 215-233.

PubMed Abstract | Publisher Full Text

Burch R, Rizzoli P, Loder E: The prevalence and impact of migraine and severe headache in the United States: figures and trends from government health studies. Headache. 2018; 58(4): 496-505.

PubMed Abstract | Publisher Full Text

Charles A: Migraine: a brain state. Curr Opin Neurol. 2013; 26(3): 235-239. PubMed Abstract | Publisher Full Text

Charles A: The migraine aura. Continuum (Minneap Minn). 2018; 24(4, Headache): 1009-1022.

PubMed Abstract | Publisher Full Text

Chong CD, Gaw N, Fu Y, et al:: Migraine classification using magnetic resonance imaging resting-state functional connectivity data. Cephalalgia. 2017: 37(9): 828-844.

PubMed Abstract | Publisher Full Text

Cybenko G: Approximation by superpositions of a sigmoidal function. Math Control Signals Syst. 1989; 2: 303-314.

Publisher Full Text

De Gooijer I, Kumar K: Some recent developments in non-linear modelling, testing, and forecasting. Int J Forecasting 1992; 8: 135-156.

Publisher Full Text

Deza L: La migraña. Acta Médica Peruana. 2010; 27(2): 129-136.

Reference Source

De la Hoz R, Rúa Ascar Z, Manuel J: Análisis de modelos de redes neuronales artificiales, para un sistema de diagnósticos de migrañas con aura y sin aura. Master Thesis Universidad Simón Bolívar. 2014.

Reference Source

Diamond S, Bigal ME, Silberstein S, et al:: Patterns of diagnosis and acute and preventive treatment for migraine in the United States: results from the American Migraine Prevalence and Prevention study. Headache. 2007; 47(3) 355-363.

PubMed Abstract | Publisher Full Text

Doupe P, Faghmous J, Basu S: Machine Learning for Health Services
Researchers. Value Health. 2019; 22(7): 808-815.

PubMed Abstract | Publisher Full Text

Evans RW, Johnston JC: Migraine and medical malpractice. Headache. 2011; 51(3): 434-440.

PubMed Abstract | Publisher Full Text

Evans RW: Diagnostic testing for migraine and other primary headaches.

Neurol Clin. 2019; 37(4): 707-725.

PubMed Abstract | Publisher Full Text

Franses PH, Van Dijk D: Non-linear time series models in empirical finance. UK: Cambridge University Press. 2000.

Publisher Full Text

García-González JR, Sánchez-Sánchez PA, Orozco M, et al.: Extracción de conocimiento para la predicción y análisis de los resultados de la prueba de calidad de la educación superior en Colombia. Formación universitaria. 2019; 12(4): 55-62.

Publisher Full Text

Giffin NJ, Ruggiero L, Lipton RB, et al:: Premonitory symptoms in migraine: an electronic diary study. Neurology. 2003; 60(6): 935-40.

PubMed Abstract | Publisher Full Text

Goadsby PJ, Holland PR: An Update: Pathophysiology of Migraine. Neurol Clin. 2019; 37(4): 651-671.

PubMed Abstract | Publisher Full Text

Goadsby PJ, Lipton RB, Ferrari MD, et al.: Migraine-current understanding and treatment. N Engl J Med. 2002; 346(4): 257-270.

PubMed Abstract | Publisher Full Text

Gormley P, Anttila V, Winsvold BS, et al: Meta-analysis of 375,000 individuals identifies 38 susceptibility loci for migraine Nat Genet 2016; 48(8): 856-66. PubMed Abstract | Publisher Full Text | Free Full Text

Headache Classification Committee of the International Headache Society: The international classification of headache disorders, 3rd edition. Cephalalgia. 2018; 38(1): 1-211.

PubMed Abstract | Publisher Full Text

Hornik K: Approximation capability of multilayer feedforward networks. Neural Netw. 1991; 4(2): 251-257.

Publisher Full Text

Hornik K, Stinchicombe M, White H: Multilayer feedforward networks are universal approximators. Neural Netw. 1989; 2(5): 359-366.

Publisher Full Text

Isaza R, Cardona E, Celis J: Cefalea: guías de práctica clínica basadas en la evidencia. Ed ASCOFAME. 1997; 42.

Publisher Full Text

Jackowski $K$, Jankowski D, Simic $D$, et al: Migraine diagnosis support system based on classifier ensemble. In: ICT Innovations. 2014; 329-339. 2014,

Springer

Publisher Full Text

Karsan N, Goadsby PJ: Biological insights from the premonitory symptoms of migraine. Nat Rev Neurol. 2018: 14(12): 699-710.

PubMed Abstract | Publisher Full Text

Koskimäki $\mathrm{H}$, Mönttinen $\mathrm{H}$, Siirtola $\mathrm{P}$, et al:: Early detection of migraine attacks based on wearable sensors: experiences of data collection using Empatica E4. In: Proceedings of the 2017 ACM International Joint Conference on Pervasive and Ubiquitous Computing and Proceedings of the 2017 ACM International Symposium on Wearable Computers (UbiComp ' 17). Association for Computing Machinery, New York, NY, USA, 2017; 506-511.

Publisher Full Text

Krawczyk B, Simic D, Simic S, et al:: Automatic diagnosis of primary headaches by machine learning methods. Central Eur J Med. 2013; 8(2): 157-165.

Publisher Full Text 
Londoño González B, Sánchez P: A Novel algorithm for detection of repetitive tasks in the keyboard. Investigación E Innovación En Ingenierías. 2015; 3(2). Publisher Full Text

Maniyar FH, Sprenger T, Monteith $\mathrm{T}$, et al.: The premonitory phase of migrainewhat can we learn from it? Headache. 2015; 55(5): 609-620.

PubMed Abstract | Publisher Full Text

Martins-Oliveira M, Akerman S, Holland PR, et al:: Neuroendocrine signaling modulates specific neural networks relevant to migraine. Neurobiol Dis. 2017; 101: 16-26

PubMed Abstract | Publisher Full Text | Free Full Text

Nikam SS: A comparative study of classification techniques in data mining algorithms. Orient J Comp Sci Technol. 2015; 8(1): 13-19.

Publisher Full Text

Qi M, Zhang P: An investigation of model selection criteria for neural network time series forecasting. Eur J Operational Res. 2001; 132(3): 666-680.

Publisher Full Text

Ramírez S, Urrea E: Capítulo 8: Guía de diagnóstico y tratamiento de la cefalea. Guía Neurológica 1, Ed Asociación Colombiana de Neurología. 2012; 141-160. Reference Source

Rasmussen BK, Olesen J: Migraine with aura and migraine without aura: an epidemiological study. Cephalalgia. 1992; 12(4): 221-228.

PubMed Abstract | Publisher Full Text

Sanchez-Sanchez P: STARD checklist for Automatic Migraine Classification Using Artificial Neural Networks. Zenodo. 2020.

http://www.doi.org/10.5281/zenodo.3872279

Sánchez-Sánchez PA, García-González JR, Perez Coronell LP: Encountered Problems of Time Series with Neural Networks: Models and Architectures,

Recent Trends in Artificial Neural Networks - from training to prediction, Ali

Sadollah and Carlos M. Travieso-Gonzalez, IntechOpen. 2019a.

Publisher Full Text

Sánchez-Sánchez PA, Zuluaga JC, Garcia Herazo D, et al:: Knowledge discovery in musical databases for moods detection. IEEE Lat Am Trans. 2019b; 17(12): $2061-2068$.

Publisher Full Tex

Sánchez-Sánchez PA, García-González JR: A new methodology for neural network training ensures error reduction in time series forecasting. $J$ Comp Sci. 2017; 13(7): 211-217.

Publisher Full Text
Sánchez-Sánchez PA, García-González JR, Rua Ascar JM: Migraine Classification Model [Source Code]. 2020a.

http://www.doi.org/10.24433/CO.2826453.v1

Sánchez-Sánchez PA, García-González JR: Autoregressive moving average recurrent neural networks applied to the modelling of colombian exchange rate. Int J Artif Intel. 2018; 16(2): 194-207.

Reference Source

Sánchez-Sánchez PA, García-González JR, Fajardo-Toro CH, et al.: Designing a neural network model for time series forecasting. Theoretical and Applied

Mathematics in International Business. 2020b; 259-284. B. Christiansen, \& F

Shuwaikh (Eds.), Hershey, PA: IGI Global.

Publisher Full Text

Schwedt TJ: Multisensory integration in migraine. Curr Opin Neurol. 2013; 26(3): $248-53$.

PubMed Abstract | Publisher Full Text | Free Full Text

Subasi A, Ahmed A, Alickovic E: Effect of flash stimulation for migraine detection using decision tree classifiers. Proc Comp Sci. 2018; 140: 223-229. Publisher Full Text

Subasi A, Ahmed A, Alickovic E, et al.: Effect of photic stimulation for migraine detection using random forest and discrete wavelet transform. Biomed Signal

Processing Control. 2019; 49: 231-239.

Publisher Full Text

Trillos CE: Migraña e investigación en epidemiología. Acta Neurológica Colombiana. 2010; 26(1): 1-4.

Reference Source

Viana M, Sances G, Linde M, et al:: Clinical features of migraine aura: Results from a prospective diary-aided study. Cephalalgia. 2017; 37(10): 979-89.

PubMed Abstract | Publisher Full Text

Wang R, Liu R, Dong Z, et al.: Unnecessary neuroimaging for patients with primary headaches. Headache. 2019; 59(1): 63-68.

PubMed Abstract | Publisher Full Text

Waring J, Lindvall Ch, Umeton R: Automated machine learning: Review of the state-of-the-art and opportunities for healthcare. Artif Intell Med. 2020; 104: 101822

Publisher Full Text

Yin Z, Dong Z, Lu X, et al.: A clinical decision support system for the diagnosis of probable migraine and probable tension-type headache based on casebased reasoning. $J$ Headache Pain. 2015; 16(29): 1-9.

PubMed Abstract | Publisher Full Text | Free Full Text 


\section{Open Peer Review}

\section{Current Peer Review Status: ? $\checkmark$}

\section{Version 2}

Reviewer Report 02 November 2021

https://doi.org/10.5256/f1000research.28066.r95716

(c) 2021 Magalhães Barros Netto S. This is an open access peer review report distributed under the terms of the Creative Commons Attribution License, which permits unrestricted use, distribution, and reproduction in any medium, provided the original work is properly cited.

\section{Stelmo Magalhães Barros Netto}

Federal University of Maranhão, São Luís, Brazil

The paper is about migraine classification from neural networks and patients' symptoms. In general, the present work is well written and the results are encouraging.

However, the population of 400 records is not enough for training a neural network, and only a part of this data is used for training. In addition, the contributions of these works are unclear, as there are many others performing the same task and using the same methods (see Trojan Fenerich et al., 2020 ${ }^{1}$ ). Thus, a larger dataset, originating from various sources, is required to not include data bias when obtaining the results.

The following points can improve the methodology and results of this work:

The method used to select the variables is not clear enough due to several models being used in addition to neural networks.

Was only the neural network used?

What are the parameters of cross-validation?

What was the size of the validation sample?

If possible, add the importance of the selected variables to Table 1.

The results in Table 2 are usually presented in terms of mean and deviation in multiple samples or even for different training sessions in the same sample for neural networks. Has this been accomplished? This information is useful to support this statement in the Discussion Section: "we observed that no over-fitting occurs to impact the classification accuracy adversely".

\section{References}

1. Trojan Fenerich A, Arns Steiner M, Nievola J, Borges Mendes K, et al.: Diagnosis of Headaches Types Using Artificial Neural Networks and Bayesian Networks. IEEE Latin America Transactions. 2020; 18 (01): 59-66 Publisher Full Text 
Is the work clearly and accurately presented and does it cite the current literature? Partly

Is the study design appropriate and is the work technically sound?

Partly

Are sufficient details of methods and analysis provided to allow replication by others? Partly

If applicable, is the statistical analysis and its interpretation appropriate? No

Are all the source data underlying the results available to ensure full reproducibility? Partly

Are the conclusions drawn adequately supported by the results?

Yes

Competing Interests: No competing interests were disclosed.

Reviewer Expertise: Machine learning; Image processing; AI

I confirm that I have read this submission and believe that I have an appropriate level of expertise to confirm that it is of an acceptable scientific standard, however I have significant reservations, as outlined above.

Author Response 09 Nov 2021

Paola Sanchez-Sanchez, Universidad Simón Bolívar, Barranquilla, Colombia

We sincerely appreciate the feedback and recommendations in this work, which we consider highly relevant and contribute to its quality.

Regarding comments:

One of the shortcomings of the study is that there are not a large number of records (400), however, the promising results offered by artificial neural network models allow them to be offered as a support to health professionals in the proper diagnosis of the different types of migraines. In order to validate the model, part of the sample was taken for training and another part for testing (80\% (320) - 20\% (80),

respectively), showing good performances in both sets. In order to give continuity to the study, especially to evaluate the occurrence of different pathologies in patients in the Colombian Caribbean region, work is being done on the construction of a larger database from multiple sources.

The article by Trojan Fenerich (2020) and some others that have emerged in recent years contribute to the discussion and demonstrate the validity of the problem and the interest of the scientific community to contribute to its solution. 
The work aims to highlight the use of artificial neural network models as a data classification technique that offers good results in the diagnosis of migraine typologies, thanks to robustness of the data management technique, adaptability, and acknowledged generalization capacity. Other techniques are also implemented in order to compare data collected using other classification techniques.

The variables presented in Table 1 correspond to a process of identification of typical characteristics associated with each type of migraine carried out by specialists in neurology who contributed to the conduct and validation of the study. A description of the variables and the values of each one can be found in (Sanchez-Sanchez et al., 2020a). We give posthumous thanks to the Neurologist Manuel Sánchez Rojas who supported this task, and he died prior to submitting the article.

Although, in the process of obtaining results, different measures, error functions were calculated and their performance was evaluated, at the time of showing it was chosen to present accuracy and precision, considering easily understandable measures that allow the results obtained to be made visible. Likewise, by sharing the data and the code, the reader is allowed to interact freely and contrast the results.

Competing Interests: No competing interests were disclosed.

Reviewer Report 03 August 2020

https://doi.org/10.5256/f1000research.28066.r64952

(C) 2020 Ordoñez Eraso H. This is an open access peer review report distributed under the terms of the Creative Commons Attribution License, which permits unrestricted use, distribution, and reproduction in any medium, provided the original work is properly cited.

\section{Hugo Ordoñez Eraso}

${ }^{1}$ Research Laboratory in Development of Software Engineering, University of San Buenaventura, Cali, Colombia

2 Universidad de Cauca, Popayán, Colombia

The paper present an model Automatic migraine classification using artificial neural. the article presents a topic of great investigative interest, it is easy to read and its common thread is easy to follow, it is also well structured.

To continue with its indexing process, the following considerations are recommended:

1. Improve image quality 2.

2. What hyperparameters were taken into account for the SVM model?

3. What was the value of the $\mathrm{K}$ neighbors that obtained the best results?

4. To better understand the results, make a graph with the data from each model. 
Is the work clearly and accurately presented and does it cite the current literature?

Yes

Is the study design appropriate and is the work technically sound?

Yes

Are sufficient details of methods and analysis provided to allow replication by others?

Yes

If applicable, is the statistical analysis and its interpretation appropriate?

Yes

Are all the source data underlying the results available to ensure full reproducibility? Yes

Are the conclusions drawn adequately supported by the results?

Yes

Competing Interests: No competing interests were disclosed.

Reviewer Expertise: data analyticsInformation retrievalsoftware engineering

I confirm that I have read this submission and believe that I have an appropriate level of expertise to confirm that it is of an acceptable scientific standard.

Author Response 09 Nov 2021

Paola Sanchez-Sanchez, Universidad Simón Bolívar, Barranquilla, Colombia

We sincerely appreciate the evaluation, which is very pertinent. We thank you so much for taking the time to perform a detailed and critical review of this work.

Competing Interests: No competing interests were disclosed.

\section{Version 1}

Reviewer Report 06 July 2020

https://doi.org/10.5256/f1000research.25589.r66038

(c) 2020 Yu S. This is an open access peer review report distributed under the terms of the Creative Commons Attribution License, which permits unrestricted use, distribution, and reproduction in any medium, provided the original work is properly cited. 


\section{Shengyuan Yu}

Medical School of Chinese PLA, Beijing, China

I have carefully read and thoroughly considered your manuscript, "Automatic migraine classification using artificial neural networks".

\section{Our comments:}

This is a meaningful idea to study the migraine classification by artificial neural networks. There are several significant problems with the description of the study and interpretation of the results.

First, the preface of the article is too wordy. We need not to describe the details of migraine as a reviews, including the epidemiology, diagnosis, differential diagnosis and treatment. In the preface, we should include the brief introduction of migraine and artificial neural networks, the current status of research on this subject, the problem in this field, why we do this study.

Second, the methods of study should include the Inclusion and exclusion criteria of the study. the reviews of classification progression of migraine should not included in this part,you can put it partial to the discussion.

Third, the discussion is too simple, we advice to discuss the present methods that using in the migraine classification and where is our comparative advantage, potential mechanism of the artificial neural networks using in the migraine classification. By the way, you can points out the direction of future research.

Is the work clearly and accurately presented and does it cite the current literature? Partly

Is the study design appropriate and is the work technically sound?

Yes

Are sufficient details of methods and analysis provided to allow replication by others? Partly

If applicable, is the statistical analysis and its interpretation appropriate? Yes

Are all the source data underlying the results available to ensure full reproducibility? Yes

Are the conclusions drawn adequately supported by the results? Yes

Competing Interests: No competing interests were disclosed.

Reviewer Expertise: Headache 


\section{I confirm that I have read this submission and believe that I have an appropriate level of expertise to confirm that it is of an acceptable scientific standard, however I have significant reservations, as outlined above.}

\section{Author Response 10 Jul 2020}

Paola Sanchez-Sanchez, Universidad Simón Bolívar, Barranquilla, Colombia

We appreciate the evaluation, which is very timely and pertinent. In response, and following the recommendations, a new version of the manuscript will be made

Competing Interests: No competing interests were disclosed.

\section{Author Response 13 Jul 2020}

Paola Sanchez-Sanchez, Universidad Simón Bolívar, Barranquilla, Colombia

We sincerely appreciate the reviewer feedback on this work and have improved the article based on your recommendations.

We have addressed each comment as follows in the article:

1. We rewrite the preface focusing the content on aspects relevant to research such as a short introduction to migraine, the current state of research in the area, the problems surrounding the classification of different types of migraine, how artificial neural networks help to solve the problems and why of this study.

2. The methods section is rewritten for better clarity in the writing. Clarifications are made regarding the inclusion and exclusion criteria, which are described in the results.

3. The discussion section was expanded to include the validation of the results with the different models applied, the significance of the results obtained, an account of some aspects that justify the development of classification models with artificial neural networks and the comparison with some studies previous. Likewise, the conclusions was expanded to include future research fields.

Competing Interests: No competing interests were disclosed. 
The benefits of publishing with F1000Research:

- Your article is published within days, with no editorial bias

- You can publish traditional articles, null/negative results, case reports, data notes and more

- The peer review process is transparent and collaborative

- Your article is indexed in PubMed after passing peer review

- Dedicated customer support at every stage

For pre-submission enquiries, contact research@f1000.com 